\title{
Population change of Common Buzzards Buteo buteo in central southern England between 2011 and 2016
}

Article

Accepted Version

Stevens, M., Murn, C. and Hennessey, R. (2019) Population change of Common Buzzards Buteo buteo in central southern England between 2011 and 2016. Bird Study, 66 (3). pp. 378389. ISSN 1944-6705 doi:

https://doi.org/10.1080/00063657.2019.1693960 Available at https://centaur.reading.ac.uk/87715/

It is advisable to refer to the publisher's version if you intend to cite from the work. See Guidance on citing.

Published version at: http://dx.doi.org/10.1080/00063657.2019.1693960

To link to this article DOI: http://dx.doi.org/10.1080/00063657.2019.1693960

Publisher: Taylor \& Francis

All outputs in CentAUR are protected by Intellectual Property Rights law, including copyright law. Copyright and IPR is retained by the creators or other copyright holders. Terms and conditions for use of this material are defined in the End User Agreement.

www.reading.ac.uk/centaur 
Central Archive at the University of Reading

Reading's research outputs online 


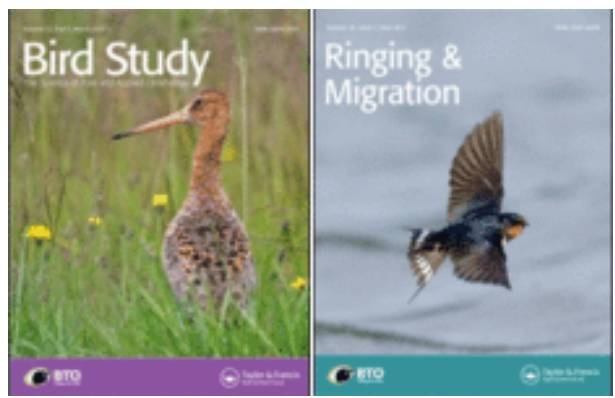

\section{Population change of Common Buzzards Buteo buteo in central southern England between 2011 and 2016}

\begin{tabular}{|c|c|}
\hline Journal: & Bird Study/Ringing \& Migration \\
\hline Manuscript ID & BS-2019-014.R2 \\
\hline Manuscript Type: & Original Article \\
\hline $\begin{array}{r}\text { Date Submitted by the } \\
\text { Author: }\end{array}$ & 12-Aug-2019 \\
\hline Complete List of Authors: & $\begin{array}{l}\text { Stevens, Matt; Hawk Conservancy Trust, Conservation \& Research } \\
\text { Murn, Campbell; Hawk Conservancy Trust, Conservation \& Research } \\
\text { Hennessey, Richard; Hawk Conservancy Trust, Conservation \& Research }\end{array}$ \\
\hline Keywords: & multiple covariates distance sampling, raptor, Population \\
\hline
\end{tabular}

\section{SCHOLARONE \\ Manuscripts}


1 Population change of Common Buzzards Buteo buteo in central southern

2 England between 2011 and 2016

3

4 Matthew Stevens*, Campbell Murn and Richard Hennessey

5

6 Conservation and Research Department, Hawk Conservancy Trust, Andover,

7 Hampshire, UK.

8

9 Population change of Buzzards

11 Keywords: multiple covariates distance sampling, raptor, population

*Corresponding author: matt@hawkconservancy.org 


\section{Abstract}

17 Capsule: Distance sampling identified an increase in estimated population size of Common Buzzards Buteo buteo in central southern England between 2011-16 of more than 50\% . The rate of population growth slowed in later years.

Aims: To assess the utility of a targeted distance sampling protocol to derive seasonal and annual population estimates for Common Buzzards across an area of southern England.

Methods: We used a line transect survey methodology and multiple covariate distance sampling to assess population density and abundance of Common Buzzards in spring and autumn between 2011and 2016 across a $2600 \mathrm{~km}^{2}$ area of central southern England.

Results: Estimated population size increased by more than 50\%, from ca. 2900 to 4500 individuals, across the period in a trend similar to that shown by Breeding Bird Survey (BBS) data. Discussion: A slowing of the growth in population size of Common Buzzards in central southern England suggests that the species may be approaching carrying capacity in this area. These results also suggest that currently employed broad scale survey methodologies adequately reflect the general population trends for this species. Our data provide the first published estimates of the 

Introduction

Identifying the population size of a species is a key step in developing and implementing an effective conservation strategy (Soulé 1987, Frankham 1995). Unfortunately, determining population size can be difficult and expensive. Difficulties can arise due to particular behaviours of the study species (e.g. mobility, shyness, crypsis, nocturnality), scarcity or its occupancy of habitats where access or movement is difficult etc. (Anderson et al. 2015). Also, the spatial scale required to produce meaningful estimates influences survey effort, the level of sampling and cost. To improve efficiency in data collection many broad-scale studies use multi-species surveys or monitoring programmes utilising volunteer fieldworkers (see e.g. Riseley et al 2008, Jiguet 2009). There are consequences to these approaches, however, and analyses must consider the effects of surveying for more than one species at a time (e.g. reduced effort per species, heterogeneity in species detectability (Johnston et al. 2014) and potential difficulties generating sufficient observations of rarer species (but see Sanderlin et al.2014)) and the variation in skills and intrinsic differences between volunteer observers (e.g. in hearing, visual acuity, level of concentration, stamina, image-processing, tiredness; e.g. Link et al. 1994, Peterjohn et al. 1995, Jiguet 2009, Eglington et al. 2010).

Species abundance and density estimates are now often generated using a distance sampling methodology. This technique uses the recorded distances of objects of interest to randomly-placed survey routes or points to estimate animal density or abundance (Buckland et al. 2001). A key assumption of this method is that all objects at zero distance $(g(0))$ are detected and that probability of detection decreases with increasing distance from the route or point. Accurate measurement of these distances is also assumed, however, it is often necessary to simplify survey methodologies (e.g. by using a small number of distance bands rather than accurate measurement) to encourage participation and adherence to protocols (Newson et al. 2008, Quesada et al. 2010). There is a trade-off between the quality of the estimate and simplicity of the method (Rabe et al. 2002) and simplification will result in detection functions that are less robust (Johnston et al. 2014), reduces 
estimated detectability (Stanbury \& Gregory 2009) and decreases the precision of derived estimates (Stanbury \& Gregory 2009, Ekblom 2010).

63

Estimates of population size for bird species in the UK tend to focus on breeding populations. These estimates are usually derived from indices of relative abundance generated as part of the Breeding Bird Survey (BBS) (e.g. Newson et al. 2008, Riseley et al. 2008, Musgrove et al. 2013). Although useful for many species, the use of the breeding pair as the unit of interest is less appropriate for certain species and will underestimate population size (Newson et al. 2008). This is particularly true for many raptor species where individuals do not breed until into their third year (Davis \& Davis 1992) and where a significant proportion of the adult population is not breeding in any one year (Newton 1979, Hunt 1998, Kenward et al. 1999, 2001), as is the case with the Common Buzzard (Buteo buteo, hereafter 'Buzzard'). Accurate estimation of population size is therefore necessary if the aim of monitoring is to provide an objective assessment of population trends - particularly where species may be increasing or decreasing. Using methodologies suitable for certain species groups to produce population estimates may then provide a means of periodically validating or calibrating indices that are applied more widely.

The Buzzard was lost from many parts of its range in Britain due to the combined effects of widespread persecution in the $19^{\text {th }}$ century, a crash in preferred prey populations (Rabbit, Oryctolagus cuniculus) in the 1950s and the effects of organochlorine pesticides in the 1960s and 1970s (Sim et al. 2000). Until the 1980s Buzzards in Britain were confined to Scotland, Wales and Western England. Since then, the enactment of improved wildlife conservation legislation (e.g. banning of organochlorine pesticides and comprehensive legal protection) and increasing public awareness have led to a significant increase in the species' population size and range. Most recent assessments indicate that the species has now recolonised many of the areas of the UK from which it had been lost (Clements 2002, Musgrove et al. 2013). 
The primary objective of this study was to use a distance sampling methodology to produce local and regional population estimates of Buzzards in central Southern England. We also draw comparisons with population estimates derived using other methodologies and discuss the utility of our approach for determining population sizes of Buzzards and other conspicuous diurnal raptor species on a larger scale.

\section{Methods}

\section{Study area and fieldwork}

The study was conducted between September 2011 and June 2016 across two areas (designated 'East' and 'West') covering ca. $2600 \mathrm{~km}^{2}$ of central southern England in Hampshire, Wiltshire, Surrey and West Sussex (centred on $1^{\circ} 18^{\prime} \mathrm{W}$ and $51^{\circ} 13^{\prime} \mathrm{N}$ - see Fig. 1). Land use within the study area is primarily mixed farming (arable and grassland) with scattered small woodlands; although the extent of woodland is higher in the East (26687ha) than West (17634ha). The study area contains ten urban areas of which five have human populations exceeding 40000 (Nomis 2016).

We used a line transect combined with distance sampling methodology (Buckland et al. 2001, 2004) to determine the population size and density of Buzzards. Each transect was a circuit based on a square with each side measuring $3 \mathrm{~km}$. Even coverage of the study area was achieved by dividing the East and West sections into 24 smaller blocks and using a random number generator to identify a grid reference and start point for transects within each of these blocks. An idealised transect route (ITR) at this location was then identified using a $3 \mathrm{~km} \times 3 \mathrm{~km}$ square overlay. Negotiating access across such a large area of private land was impractical and so transects made use of public rights of way and open access land, the ITR serving as a point of spatial reference to facilitate the identification of a circuit of appropriate length through the selected area. Transects followed the ITR 
as closely as possible. Where deviations were necessary, alternative routes prioritised open access land and other rights of way types before roads in an effort to reduce bias associated with following obvious linear landscape features (surfaced roads, field edges, fences and hedgerows; Ortega \& Capen 2002, Marques at al. 2009). Edge effects were minimised by including all randomised start locations even when these resulted in the transect breaching the study area boundary. In these cases, only the lengths of transect within the study area were included in analyses.

Surveys were performed in ten transect periods, two each year, between Sep-Dec ('autumn') 2011 and Feb-May ('spring') 2016. Two seasonal transect periods were used to enable assessment of expected fluctuations in density associated with post-breeding abundance and overwinter mortality. Transects started between 08.30 and 10.00 from a randomised start point and took 3-7 hours to complete. The direction (anti- or clockwise) of travel was also randomised. Each transect was performed by one of two fieldworkers (MS or RH). Transects were walked only on days with no rain, good visibility and when wind strength was no greater than Beaufort force four.

All birds observed during the walked transects were recorded. When groups of birds were encountered, the number of individuals was noted. For each observation, observer location was recorded using Garmin 60 Csx GPS units and horizontal distance and bearing to each bird (or to the centre point of groups; Buckland et al. 2001) from the observer using Swarovski Laser Guide $8 \times 30$ or Nikon Forester 550 laser rangefinders and Silva compasses. Where a bird in flight had obviously been disturbed from a perch by the fieldworker just prior to detection, measurement of distance was taken from the fieldworker location to the original perch. Bird behaviour, situation (i.e. flying, perched or on the ground), habitat, time of observation and weather conditions were also recorded for each observation. To minimise double-counting, fieldworkers noted, where possible, the plumage morph of all birds (following Glutz von Blotzheim et al. (1971)), specific aspects of plumage (e.g. bright tail, prominent breast patches etc.) and location of obvious moult (in remiges or 
rectrices). Where there was still uncertainty regarding the status of an individual, the observer noted their confidence in the observation being new on a percentage scale where ' 0 ' indicated a certainty that the individual had already been recorded, and '100' where it had not. Bird movement and relative timings and location of previous observations were used to inform this assessment. This enabled later exclusion of observations from analyses, based on confidence. We adopted a conservative approach to inclusion of data, retaining only those where confidence exceeded $70 \%$.

Where the ability of a fieldworker to detect birds was compromised by visibility from the transect route (e.g. obstruction by surrounding vegetation), the observer moved a short distance away from the transect to obtain a clearer view before returning and continuing along the route. Although the fieldworker followed a map of the transect route it is unlikely that they will have been standing exactly on the transect line (i.e. at $g(0)$ - zero distance from the line) at the time of making any observation. The perpendicular distance of the fieldworker from the transect route at the time of each observation was determined using the GPS locations viewed in GIS. These 'offsets' were then used to correct the calculated distances of the observations to the transect line through either addition or subtraction of the offset (depending on the relative positions of the observer and bird to the transect route). All GPS locations obtained using WGS-84 were transformed to British National Grid using the Ordnance Survey 'OSTN02' transformation in ArcGIS (ESRI 2011).

The restriction of transect routes to public rights of way and open access areas may have resulted in the violation of the distance sampling assumption that all areas have equal probability of being sampled. We determined the extent of entire study area unavailable for surveying using the 'Buffer' function in ArcGIS (ESRI 2011). In this we produced a survey strip corresponding to the maximum operational distance of the rangefinder $(700 \mathrm{~m})$ on each side of all rights of way and open access areas and deducted the extent of study area not covered by these strips $\left(5.8 \mathrm{~km}^{2}\right)$ from the total size of the study area in all subsequent distance analyses. 
To investigate the possible role of roads and roadside areas in attracting birds, we also compared the distribution of distances of 5000 randomly-generated points with that of our observations. Points were generated using the random number generator runif() function in $\mathrm{R}$ ( $\mathrm{R}$ Core Team 2016) to produce pairs of latitude and longitude. These points were then plotted and their distances from the nearest road determined using the Near function in ArcGIS. The distributions of these 'distanceto-roads' measurements were compared using two-sample Kolmogorov-Smirnov tests.

\section{Density estimation}

Population size and density estimates were derived using both the Conventional Distance Sampling

(CDS) and Multiple Covariates Distance Sampling (MCDS) engines within program Distance 7.0

(Thomas et al. 2010). Distance analysis here follows the guidelines provided for that software and in the associated literature by Buckland et al. $(2001,2004)$.

Five covariates (Table 1) were included in the MCDS modelling process on the basis that each was

assumed a priori to influence the ability to detect birds through a biological or methodological effect (Burnham 1981, Thompson 2002, Diefenbach et al. 2003). A two-level factor covariate (OBS) was included to account for the likely variation in ability of fieldworkers to detect birds. Area of woodland at the point of observation (WDS) is also likely to impact detection distance due to an inverse relationship with range of view (i.e. the maximum range of vision). Values for this covariate were determined from the CEH Land Cover Map 2007 (Morton et al. 2014) by measuring the area of woodland within a $250 \mathrm{~m}$ radius of the point of observation using ArcGIS 10.2 (ESRI 2011). STRATA was included as a covariate in order to account for potential differences in topography or habitat quality between the two sections of the study area, since this may result in differential detection distances. Bird activity and behaviour, and thus detectability, will vary throughout the day (e.g. 
Kendall 2014, Öberg et al. 2015). Here, TIME was defined as the number of minutes after sunrise for each observation. Lastly, the situation of the bird, i.e. whether on the ground, perched or in flight, was included as a factorial covariate, LOC. The inclusion of flying birds in distance sampling can present a number of problems, primarily due to violation of the assumption of uniform distances through responsive movement, and double-counting (see Fewster et al. 2008, Anderson et al. 2015). exclusion of flying birds from analyses is possible, this approach is best used for species in which only a small proportion of the population will be in flight at any one time (Buckland et al. 2008). This is clearly not the case for many soaring raptor species and exclusion of such data was not appropriate. Instead, we adopted a 'look-ahead' approach to improve the likelihood of birds being recorded before they responded to the presence of the fieldworker (Burnham et al. 1980, Anderson et al. 2015).

Relationships between covariates and the ability to detect birds were explored prior to modelling, although failure to detect any effect here did not prevent inclusion in model assessments. Factor covariates were tested against perpendicular distance using either Welch's t-tests or ANOVA. Exploration of the potential relationship between continuous, non-factor covariates and distance was performed using Pearson's $r$ and regression.

Models with uniform, half-normal and hazard-rate key functions were fitted to the data. Automatic addition of adjustment terms was enabled for analyses using CDS. For the MCDS engine, however, this was restricted to a maximum of two cosine, simple polynomial or hermite polynomial adjustment terms. Model fit was assessed with reference to cosine-weighted Cramér-von Mises and Kolmogorov-Smirnov tests. Data were truncated at $550 \mathrm{~m}$ to remove a lengthy tail and all models incorporating adjustment terms were scaled by the truncation distance. 
Overloading of the MCDS engine with covariates is more likely to result in failure of the algorithm to converge (Thomas et al. 2010). To counter this, we follow the guidelines of Thomas et al. (2010) who advocate the forward stepwise addition of individual covariates, retaining those which contribute to reducing Akaike's Information Criteria (AIC). AIC was used to select between models (Burnham \& Anderson 2002).

All statistical analyses, other than distance sampling, were performed using R version 3.3.1.

\section{Results}

$4490 \mathrm{~km}$ of surveys were completed during the 10 transect periods (Table 2). Coverage was higher in the eastern section of the study area with $2295 \mathrm{~km}$ of surveys walked on 151 transects compared with $2194 \mathrm{~km}$ on 145 transects in the western section. The average duration of each transect was 371 minutes (365 in Spring vs 377 in Autumn).

4274 observations of 5174 individuals were made during the study. Birds were seen in groups of up to 32 individuals, however, $85 \%$ of observations were of single birds (mean group size $=1.2 \pm 0.75$ ). $63 \%$ of observations were of birds in flight (cf. $37 \%$ perched or on the ground). Of these, $62 \%$ were birds which were soaring, hovering or interacting with other species, rather than in obvious directional transit movements.

There was no difference between the distributions of number of observations and the number of transects walked (and therefore, transect length) for each season (autumn $X^{2}(4)=3.08, p=0.55$; spring $\left(X^{2}(4)=1.75, p=0.78\right)$ indicating that more observations were made when more transects were walked. Significantly more individuals were seen during spring surveys than in autumn $\left(X^{2}(3)=\right.$ $160.25, p<0.001)$ despite the total length of surveys undertaken being similar. 
Histograms of the distribution of perpendicular distances indicated detection on and close to the transect line remained at or near $100 \%$ in all survey periods. Median detection distance across all data was $178 \mathrm{~m}$. Truncation of data above $550 \mathrm{~m}$ resulted in the loss of $2.8 \%$ of observations (99 observations of 143 individuals) but left more than 330 observations per period; comfortably above the threshold of 60-70 generally recommended for modelling using Distance (Buckland et al. 2001).

Sufficient data were available to enable the modelling of separate detection functions, and the inclusion of different covariates, for each period.

$55 \%$ of the total length of transects was walked along roads. $28 \%$ of all observations involved Buzzards within $100 \mathrm{~m}$ of any road and only $11 \%$ were of birds within $100 \mathrm{~m}$ of the same road as that from which the observation was made. There was no indication of a bias in observation of birds near to roads when comparing the distribution of distances with that of 5000 random locations (two-sample Kolmogorov-Smirnov, $D-<0.001, p=0.99$; Buzzard median $-264 \mathrm{~m}$, Random median $158 \mathrm{~m}) .36 \%$ of the random locations were within $100 \mathrm{~m}$ of a road compared with $21 \%$ of Buzzard locations

\section{Exploratory analyses of covariates}

The distance at which birds were detected reduced as the extent of woodland at the point of observation increased. This effect was negative across the entire dataset $\left(r=-0.166, t_{4157}=-10.8, p\right.$ $<0.001)$ and in all survey periods $(p<0.002)$ except spring $2013\left(r=-0.079, t_{363}=-1.51, p=0.13\right)$.

None of the remaining covariates showed any consistent relationship with detection distance. Mean detection distances were similar between both sections of the study area and varied significantly only in 2012 (spring, $t_{474.13}=-3.5, p<0.001$, mean East $-178.9 \mathrm{~m}$, West $-207.7 \mathrm{~m}$; autumn, $t_{255.2}=-$ 
2.06, $p=0.04$, mean East $-179.2 \mathrm{~m}$, West $-214.2 \mathrm{~m}$ ). The situation of birds (i.e. whether on the ground, perched or in flight) had no significant influence on detection distance (ANOVA $F_{2,4156}=2.42$, $p=0.09$, Tukey test, $p>0.15$ ). Observer effects on detection distances were identified in one of the four survey periods where data were collected by more than one fieldworker (spring 2013, $t_{139}=$ 3.67, $p<0.001$, mean $\mathrm{MS}-208 \mathrm{~m}, \mathrm{RH}-148 \mathrm{~m})$. Although timing of an observation had a bearing on detection distance in two periods (autumn 2012, $F_{1,402}=4.91, p=0.027$; and spring $2015, F_{1,307}=$ 5.99, $p=0.015)$, there was no significant effect during the other eight periods.

\section{Model fitting}

MCDS models having reasonable fit (i.e. with Cramér von Mises and Kolmogorov-Smirnov tests $p>$ 0.3) were developed for all periods (Table 3) except periods 5-7. Although statistics assessing model fit for these periods produced $p>0.1$, their detection functions and quantile-quantile plots indicated that more birds than expected were observed close to the transect route. As model fit was reasonable in these periods, we still present the outputs from these but emphasise their being on the margins of acceptability. CDS models were preferred in period $7(p>0.5)$, however, the model with lowest AIC (Half-normal + three cosine adjustments) showed signs of over-fitting and issues in maintaining monotonicity. A model using CDS with a Uniform key function is preferred for this period. Among the MCDS models, TIME, WDS/WDD and STRATA had the greatest effect on AIC, and appeared in the majority of preferred models for each survey period.

\section{Population estimates}

Population size and density estimates increased throughout the course of study and were 0.6 birds $\mathrm{km}^{-2}$ higher by 2016 than at the start of the study. Our analyses suggest an increase in estimated population size of 56\%, from 2883 individuals in 2011 to 4485 in 2016 (Table 4). The average annual 
rate of increase across the four-and-a-half years of the study was $12.5 \%$ but this slowed in successive years (from $15 \%$ to $1 \%$ in autumn and $43 \%$ to $-1 \%$ in spring; Figure 2 ).

296

297

More birds were seen in spring surveys $\left(1.31 \mathrm{~km}^{-1}\right)$ than preceding autumn periods $\left(1.0 \mathrm{bird} \mathrm{km} \mathrm{km}^{-1}\right)$ 2012-spring 2013. Estimated density was also consistently higher for surveys performed during the spring (Table 4; means: spring - 1.59 autumn - 1.44).

301

302

\section{Discussion}

\section{Population density estimates}

We used a distance sampling-based methodology to estimate the population density of a conspicuous diurnal raptor species within an area of central southern England. These estimates indicate that the Buzzard population increased by more than $50 \%$ over the course of the study

(Figure 2). In contrast, Buzzard populations in the adjacent SW region have shown a comparatively modest rate of increase since 1995 (+13\% - Harris et al. 2017). Differences in the rate of population change between these two regions may be a function of there being a higher number of available potential territories in regions neighbouring the SW population and the consequent dispersal of individuals from higher to lower density areas (Walls \& Kenward 1998).

The reduced rate of population growth during the last three survey periods mirrors estimates derived from BBS data for the SE region (www.bto.org/bbs) which, although showing an overall increase of $1104 \%$ since 1995 , indicate a slowing of population growth to a point of a slight decline (2\%) between 2016-17. The reasons for this are unclear, especially since rates of breeding success for 
regional differences will be masked in these national estimates. Nevertheless, a number of factors may be operating to limit population growth, including: the ongoing impacts of viral haemorrhagic disease (VHD) on UK rabbit populations (Harris et al. 2019), the abundance of which has been shown to influence breeding productivity and population increase in Buzzards in the UK (Graham et al.1995; Swann \& Etheridge 1995); the continued impacts of secondary poisoning by rodenticides (e.g.

Christensen et al. 2012) and ingestion of lead in spent ammunition (Pain et al. 2009); and a potential increase in persecution in response to the perceived predation pressures on game bird populations from increasing Buzzard abundance.

Despite the observed declines between 2016-17 in this study and BBS, continued population growth in areas of the SE region which lie to the north and east of the study area still appears likely since they will have been recolonised later and will be further from reaching carrying capacity; a situation highlighted by Harris et al. (2014). In addition, now that the scale of human-induced population constraints appears to have substantially reduced, carrying capacities are likely to have increased and be governed mostly by the availability and suitability of food and breeding habitat. In southern England, there is likely to be a proportionally greater extent of suitable breeding habitat in the SE region compared to the historical strongholds in the SW since the landscape is more heavily wooded (Forestry Commission 2016). As a result, continued population growth in this region is likely for the foreseeable future.

Atlas data (Balmer et al. 2013) show the Buzzard to be uniformly distributed across all 10x10km squares of SE England and from more than $85 \%$ of all $2 \mathrm{~km} \times 2 \mathrm{~km}$ tetrads covered by atlas fieldwork (2007-2012) in the SE region. Assuming that habitat quality and availability within our study area is representative of that throughout the remainder of the SE region, then our density estimates indicate a population size of 27500-32500 individuals in SE England. Translation of this figure into an estimate of the breeding population is difficult, since a significant proportion of Buzzards will not 
make a nesting attempt each year, either due to immaturity, lack of status and inability to find a mate or hold a territory (Davis \& Davis 1992, Kenward et al. 2000). Using the estimate suggested by Kenward et al. (2000) of only one in four individuals breeding each year, results in an estimate of between 3440-4125 pairs in SE England. This represents a breeding density of $18-22$ pairs per $100 \mathrm{~km}^{2}$, similar to that found by Sim et al. (2001) in one of their West Midlands study areas. This is still lower than the 41 pairs $100 \mathrm{~km}^{-2}$ recorded by Newton et al. (1982) across a large area in midWales, and substantially lower than the densities (78 pairs $\left.100 \mathrm{~km}^{-2}\right)$ recorded in ideal wooded habitat in central Europe (Melde 1956, Thiollay 1967). Since the coarse regional population estimate presented here is an extrapolation from our derived estimates, any variation in the quality of those landscape characteristics representing suitability for Buzzards (e.g. food and prey density, disturbance, persecution, habitat structure and mosaic etc.) will influence its validity.

Alongside the estimates of overall abundance within the study area, our study provides an interesting comparison of the apparent abundance of Buzzards between autumn and spring periods. Several studies have determined that juvenile Buzzards tend to remain within their natal territory for the first few months after fledging (Davis \& Davis 1992, Walls et al. 1999) and that most do not disperse more than $50 \mathrm{~km}$ from the natal site in their first year (Walls \& Kenward 1998). This is particularly the case in landscapes with a significant arable component (Walls et al. 1999) where Buzzards often exploit the easy foraging for invertebrates provided by ploughed fields (Dare 1957). As a result, there is unlikely to have been any significant loss of first year birds from the study area in the autumn, and in fact we expected higher densities for surveys in this period. The potential impacts of overwinter and courtship mortality (Tubbs 1974, Simpson 1993) would theoretically compound this expected difference in seasonal abundance. That this is not the case may reflect more on seasonal variation in bird behaviour, and its influence on detectability, than demographics. Increased time spent soaring and in display behaviours in spring resulted in improved detectability during spring surveys. The supplementation of the autumn population by juveniles will also have 
been offset by dispersal (Walls \& Kenward 1995) and high rates of mortality for Buzzards in the four months after fledging (Kenward et al. 2001).

\section{Methodological assessment}

We encountered few obvious methodological issues with the study. Poor model fit using the MCDS engine for the autumn 2014 was most likely the result of higher than expected numbers of birds recorded between $275-325 \mathrm{~m}$ in this survey period. This problem was not identified in other periods suggesting that it is unlikely to represent any significant issue with survey design. Similarly, the issue of poor precision was limited to one survey period and stems from reduced coverage; the level of effort being lowest in this period (Table 2).

The covariates most frequently included within preferred models (WDS, STRATA and TIME) indicate that woodland cover was the most important factor affecting Buzzard detectability. Increasing density of woodland reduces the view of surrounding habitats leading to birds generally being detected at shorter distances than in more open habitats. This effect is also likely to account for the inclusion of STRATA in many preferred models since a greater proportion of the landscape area was woodland (and, therefore, a higher proportion of surveys performed through woodlands) in the eastern section of the study area. Lastly, the inclusion of TIME is likely to relate to the behaviour of birds at differing times of the day e.g. birds perched during cooler periods (during morning) and soaring in warmer periods (from late morning onwards). The level and type of activity of birds will have an obvious impact on detection distance. Daily variation in temperature and weather conditions will make this a complicated relationship which is unlikely to be detected by these analyses.

Transects running through dense woodland may result in undetected responsive movements of birds which may, in turn, lead to incorrect distance measurement or incomplete detection at $g(0)$. In 
such habitats Buzzards were almost always heard to call prior to, or immediately after, taking flight when disturbed by a fieldworker. Use of such cues to identify original locations for measurement should have reduced the number of undetected responsive movements along transects performed in these habitats.

402

The use of public rights of way and roads for this study will have resulted in some sections of transect necessarily following linear landscape features such as hedgerows, fences and runs of power lines and poles. These features can influence the distribution of raptors such as Buzzards through their impact on the abundance of preferred prey items (e.g. Adams \& Geiss 1983, Meunier et al. 2000) or carrion (Lambertucci et al. 2009, Lees et al. 2013), the ways in which they can improve hunting efficiency (e.g. Beckmann \& Shine 2011) or how they permit the adoption of less energydemanding hunting strategies (Meunier et al. 2000). Failure to place transects randomly across a study area (e.g. by following linear landscape features) can lead to biases arising from the association and preferences for certain habitats or landscape features. This will effectively remove the validity of extrapolating sample statistics to the population of interest (Buckland et al. 2001). Despite this, and the potential effects listed above, we found no evidence for the attraction of Buzzards to roads in our data. Whether the inclusion of roadside transect data has a significant influence on the derived density estimates is open to question.

Although we adopted a number of strategies to reduce double counting, the duration of each transect (mean - 371 minutes) means that there was ample opportunity for birds to move across the study area. This is likely to have resulted in the double-counting of a small number of individuals and possible positive bias to our estimates. Similarly, the inclusion of flying birds may also have

421 affected our results. Buckland et al. (2001) suggest that independent movement of birds can be accommodated they must, 'on average', be moving at less than half the speed of the observer if they are not to introduce a positive bias to the results. $24 \%$ of the observations here were of birds 
engaged in purposeful, directional flight. Since neither the destination of flying birds nor their duration of flight was recorded here, it is not possible to determine whether the average speed of these individuals was less than half that of the observer. Whether the inclusion of these observations has resulted in a significant positive bias to estimates is open to question. Nevertheless, inclusion of some assessment of the nature and distances of flight behaviour in future surveys would enable greater discrimination of data and exploration of impacts on derived estimates.

431

The population trends derived here closely follow those obtained for the same period by BBS. This suggests that the potential issues often associated with broad-scale, multi-species, volunteer surveys (e.g. the dilution of effort between target species and differential abilities of volunteers) have little effect on results. This may not be the case for density estimates though, since the use of a small number of distance bands (in BBS), rather than accurate distance measurement, has been shown to over-estimate density (Quesada et al. 2010). The extent of any difference cannot be assessed here since there are no published BBS-derived population estimates for this species in this region for the period covered by our study.

The methods employed here provide a reasonably straightforward means of assessing the absolute population size of an abundant, conspicuous, raptor species across the UK landscape. However, this methodology is unlikely to be suitable for more secretive (e.g. Sparrowhawk, Accipiter nisus) or scarcer species. The methods used here are applicable across most landscape types and could provide a useful means of population monitoring stratified by habitat and area. The broader application of such methods is perhaps limited by the cost of equipment (laser rangefinder and gps);

447 however, rapid technological advances and falling costs are likely to remove such obstacles in the near future. Individual variation in skill levels, abilities to detect birds in the landscape and the need 
to train individuals in survey methodology may also pose certain problems; however, these are challenges faced by all survey protocols.

451

The recovery of raptor populations is often accompanied by concerns relating to potential impacts on conservation (e.g. of prey species or competitors; e.g. Moleón et al. 2011), sociology (e.g. Burke et al. 2015) or economy (e.g. of game populations; e.g. Parrot 2015). Indeed, the recovery of Buzzard populations has been followed by increasing pressure for population control measures to protect game stocks (Lees et al. 2012). Although Buzzards are protected under UK law (Wildlife \& Countryside Act 1981), provision exists to issue licences to kill individuals to prevent agricultural damage (including 'damage to livestock'). Licences are issued only after careful consideration of a number of factors, including local abundance. Without accurate population data, such assessments will be affected by subjective perceptions of abundance. Producing estimates of actual population size for this species is therefore timely, and will prove useful in assisting decision-makers in assessing the potential impacts of any licensed action.

\section{Conclusion}

Our results show how the population size of a previously persecuted species of raptor in central southern England has increased by more than $50 \%$ over a five year period, and how the previously high rate of population growth appears to be stalling. The next phase of this study will focus on producing density estimates using this methodology across a larger area. This approach will enable comparison of the predicted population estimates for the SE region produced here with those utilising fieldwork undertaken across all parts of the region and a direct comparison with BBS estimates. Further assessment of the utility of this method and the viability of using volunteers to derive estimates across a broader geographical scale will also be possible. 


\section{Acknowledgements}

476 This work was funded by the visitors and supporters of the Hawk Conservancy Trust. The John

477 Spedan Lewis Foundation assisted with funding for the purchase of essential equipment. Two

478 anonymous reviewers provided helpful comments on earlier drafts of the manuscript.

479 


\section{References}

481

482

Adams. L.W. \& Geiss, A.D. 1983. Effects of roads on small mammals. J Appl. Ecol. 20: 403-415.

483

484

Anderson, A.S., Marques, T.A., Shoo, L.P. \& Williams, S.E. 2015. Detectability in audio-visual surveys

of tropical rainforest birds: the influence of species, weather and habitat characteristics. PLOS ONE

10(6): e0128464. Doi:10.1371/journal.pone.0128464.

487

Balmer, D.E., Gillings, S., Caffrey, B.J., Swann, R.L., Downie, I.S. \& Fuller, R.J. (eds) 2013. Bird Atlas

2007-11: the breeding and wintering birds of Britain and Ireland. BTO Books, Thetford.

490

491

Beckmann, C., \& Shine, R. 2011. Toad's tongue for breakfast: exploitation of a novel prey type, the

invasive cane toad, by scavenging raptors in tropical Australia. Biol. Invasions 13(6): 1447-1455.

493

494

BTO. (n.d.) Retrieved from https://www.bto.org/volunteer-surveys/bbs/latest-results/population-

trends

496

497

Buckland, S.T., Anderson, D.R., Burnham, K.P., Laake, J.L., Borchers, D.L. \& Thomas, L. 2001.

Introduction to distance sampling. Oxford: Oxford University Press.

499

500

Buckland, S.T., Marsden, S.J. \& Green, R.E. 2008. Estimating bird abundance: making methods work.

Bird Conserv. Int.18:S91-S108.

502

503

Burke, B.J., Finna, A., Flanagan, D.T., Fogarty, D.M., Foran, M., O’Sullivan, J.D., Smith, S.A., Linnell,

J.D. and McMahon, B.J., 2015. Reintroduction of White-tailed Eagles to the Republic of Ireland: A 
Burnham, K., Anderson, D., \& Laake, J. 1980. Estimation of density from line transect sampling of

biological populations. Wildlife Monogr. 72:7-202.

509

510

Burnham, K.P. 1981. Summarizing remarks: Environmental influences. Studies Avian Biol-Ser. 6:324-

Christensen, T.K., Lassen, P. \& Elmeros, M. 2012. High exposure rates of anticoagulant rodenticides

in predatory bird species in intensively managed landscapes in Denmark. Archives of Environmental

Contamination and Toxicology 63:437-444.

516

Clements, R. 2002. The Common Buzzard in Britain: a new population estimate. Brit. Birds 95:377383.

Dare, P.J. 1957. The post-myxomatosis diet of the buzzard. Devon Birds 10:2-6.

521

522

Davis, P.E. \& Davis, J.E. 1992. Dispersal and age of first breeding of buzzards in central Wales. Brit.

Birds 85: 578-597.

524

525

Dean, W.R.J. \& Milton, S.J. 2003. The importance of roads and road verges for raptors and crows in 526 the succulent and Nama-Karoo, South Africa. Ostrich 74(3-4):181-186.

527

528 Diefenbach, D.R., Brauning, D.W. \& Mattice, J.A. 2003. Variability in grassland bird counts related to observer differences and species detection rates. Auk 120(4):1168-1179. 
531 Eglington, S.M., Davis, S.E., Joys, A.C., Chamberlain, D.E. \& Noble, D.G. 2010. The effect of observer experience on English breeding bird survey population trends. Bird Study 57:129-141

533

534

Ekblom, R. 2010. Evaluation of the analysis of distance sampling data: a simulation study. Ornis

Svecica 20:45-53

536

ESRI 2011. ArcGIS Desktop: Release 10. Redlands, CA: Environmental Systems Research Institute.

538

Faanes, C.A. \& Bystrak, D. 1981. The role of observer bias in the North American breeding bird survey. Studies Avian Biol-Ser. 6:353-359.

541

Fewster, R.J.M, Southwell, C., Borchers, D.L., Buckland, S.T. \& Pople, A.R. 2008. The influence of animal mobility on the assumption of uniform distances in aerial line-transect surveys. Wildlife. Res. 35: $275-288$

545

Forestry Commission. 2016. National Forest Inventory Woodland England 2015.

547

Forman, R.T.T. \& Alexander, L.E. 1998. Roads and their major ecological effects. Annu. Rev. Ecol.

Syst. 29:207-231.

550

Frankham, R. 1995. Effective population size/adult population size ratios in wildlife: a review. Genet.

552 Res. 66(2), 95-107.

553

554 Glutz von Blotzheim, U., Bauer, K. \& Bezzel, E. 1971. Handbuch der Vögel Mitteleuropas, Vol. 4. Aula Verlag, Wiesbaden. 
557

558

559

560

561

562

563

564

565

566

567

568

569

570

571

572

573

574

575

576

577

578

579

580

581

582

Harris, S.J., Risely, K., Massimino, D., Newson, S.E., Eaton, M.A., Musgrove, A.J., Noble, D.G., Procter, D. \& Baillie, S.R. 2014. The Breeding Bird Survey 2013. BTO Research Report 658. British Trust for Ornithology, Thetford.

Harris, S.J., Massimino, D., Gillings, S., Eaton, M.A., Noble, D.G., Balmer, D.E., Procter, D. \& PearceHiggins, J.W. 2017. The Breeding Bird Survey 2016. BTO Research Report 700. British Trust for Ornithology, Thetford.

Harris, S.J., Massimino, D., Eaton, M.A., Gillings, S., Noble, D.G., Balmer, D.E., Pearce-Higgins, J.W. \& Woodcock, P. 2019. The Breeding Bird Survey 2018. BTO Research Report 717. British Trust for Ornithology, Thetford.

Hunt, W.G. 1998. Raptor floaters at Moffat's equilibrium. Oikos 82: 191-197.

Jiguet, F. 2009. Method learning caused a first-time observer effect in a newly started breeding bird survey. Bird Study 56: 253-258.

Johnston, A., Newson, S.E., Risely, K. Musgrove, A.J., Massimino, D., Baillie, S.R. \& Pearce-Higgings, J.W. 2014. Species traits explain variation in detectability of UK birds. Bird Study 61: 340-350.

Kendall, C.J. 2014. The early bird gets the carcass: Temporal segregation and its effects on foraging success in avian scavengers. The Auk: Ornithological Advances 131:12-19.

Kenward, R.E., Marcström, V. \& Karlbom, M. 1999. Demographic estimates from radio-tagging: models of age-specific survival and breeding in the goshawk. J. Anim. Ecol. 68: 1020-1033. 
583 Kenward, R.E., Walls, S.S., Hodder, K.H., Pakhala, M., Freeman, S.N. \& Simpson, V.R. 2000. The 584 prevalence of non-breeders in raptor populations: evidence from rings, radio-tags and transect surveys. Oikos 91:271-279.

586

587

Kenward, R.E., Walls, S.S. \& Hodder, K.H. 2001. Life path analysis: scaling indicates priming effects of 588 social and habitat factors on dispersal distances. J. Anim. Ecol. 70:1-13.

589

Knight, R.L. \& Kawashima, J.Y. 1993. Responses of Raven and Red-tailed Hawk populations to linear 591 right-of-ways. J. Wildlife Manage. 57(2):266-271.

592

Lambertucci, S.A., Speziale, K.L., Rogers, T.E. \& Morales, J.M. 2009. How do roads affect the habitat use of an assemblage of scavenging raptors? Biodivers. Conserv. 18(8):2063-2074.

595

596

00: 1-4. https://doi.org/10.1111/j.1755-263X.2012.00301.x

598

599

600

Link, W.A., Barker, R.J. \& Sauer, J.R. 1994. Within-site variability in surveys of wildlife populations. Ecology 75: 1097-1108.

601

602

Marques, T.A., Buckland, S.T., Borchers, D.L., Tosh, D. \& McDonald, R.A. 2010. Point transect

603 sampling along linear features. Biometrics 66:1247-1255.

604

Melde, M. 1956. Die Mausebussard. Neue Brehm Bucherei, Leipzig.

606

607

Meunier, F.D., Verheyden,C., \& Jouventin, P. 2000. Use of roadsides by diurnal raptors in agricultural 608 landscapes. Biol. Conserv. 92:291-298. 
Moleón, M., Sánchez-Zapata, J.A., Gil-Sánchez, J.M., Barea-Azcón, J.M., Ballesteros-Duperón, E. and

Virgós, E., 2011. Laying the foundations for a human-predator conflict solution: assessing the impact

of Bonelli's eagle on rabbits and partridges. PLoS One, 6(7), p.e22851.

613

614

Morelli, F. Beim, M., Jerzak, L., Jones, D. \& Tryjanowski, P. 2014. Can roads, railways and related

Morton, R.D., Rowland, C.S., Wood, C.M., Meek, L., Marston, C.G. \& Smith, G.M. 2014. Land Cover

Map 2007 (vector, GB) v1.2. NERC Environmental Information Data Centre.

Musgrove, A., Aebischer, N., Eaton, M., Hearn, R., Newson, S., Noble, D., Parsons, M., Risely, K. \&

Stroud, D. 2013. Population estimates of birds in Great Britain and the United Kingdom. Brit. Birds $106,64-100$.

623

Newson, S.E., Evans, K.L., Noble, D.G., Greenwood, J.J.D. \& Gaston, K.J. Use of distance sampling to improve estimates of national population sizes for common and widespread breeding birds in the UK. J. Appl. Ecol. 45:1330-1338.

627

Newton, I. Davis, P.E., \& Davis, J.E. 1982. Ravens and buzzards in relation to sheep farming and forestry in Wales. J. Appl. Ecol. 19: 681-706.

630

Nomis - Official Labour Market Statistics. 2016. KS101EW (Usual resident population). Available from: http://www.nomisweb.co.uk/census/2011/ks101ew [Accessed August 2018]. 
634 Öberg, M., Arlt, D., Pärt, Laugen, A.T., Eggers, S \& Low, M. 2015. Rainfall during parental care reduces reproductive survival components of fitness in a passerine bird. Ecol. Evol. 5:345-356.

636

637

Ortega, Y.K. \& Capen, D.E. 2002. Roads as edges: Effects on birds in forested landscapes. Forest Sci.

638 48:381-390.

639

Pain, D.J., Fisher, I.J. \& Thomas, V.G. 2009. A global update of Lead poisoning in terrestrial birds from

640 ammunition sources, In Watson, R.T., Fuller, M., Pokras, M. \& Hunt, W.G. (eds) Ingestion of Lead from Spent Ammunition: Implications for Wildlife and Humans. The Peregrine Fund, Boise, Idaho, USA.

643

Parrott, D., 2015. Impacts and management of common buzzards Buteo buteo at pheasant

Phasianus colchicus release pens in the UK: a review. European Journal of Wildlife Research, 61:181197.

Peterjohn, B.G., Sauer, J.R., \& Robbins, C.S. 1995 Population trends from the North American breeding bird survey. In Martin, T.E. \& Finch, D.M. (eds) Ecology and Management of Neotropical Migratory Birds: 3-39. Oxford University Press, New York.

651

Pollock, K.H., Nichols, J.D., Simons, T.R., Farnsworth, G.L., Bailey, L.L, \& Sauer, J.R. 2002. Large scale wildlife monitoring studies: statistical methods for design and analysis. Environmetrics 13:105-119. with band allocation is negligible in large scale bird monitoring schemes, but how precise is the use of bands at all? Ardeola 57:23-32. 
659 R Core Team. 2016. R: A language and environment for statistical computing. R Foundation for

660 Statistical Computing, Vienna, Austria. URL https://www/R-project.org/.

661

662

Rabe, M. J., Devos, S. S. \& Rosenstock Jr, J.C. 2002. Review of big-game survey methods used by

663

wildlife agencies of the western United States. Wildlife Soc. B. 30:46-53.

664

665

Ralph, C.J. \& Scott, J.M. Eds. 1981. Estimating numbers of terrestrial birds. Studies Avian Biol.-Ser 6.

666

667

Ramsey, F.L. \& Scott, J.M. 1981. Tests of hearing ability. Studies Avian Biol.-Ser 6:342-345.

668

669

Riseley, K., Noble, D.G., \& Baillie, S.R. 2008. The breeding bird survey 2007. BTO Research Report

670

508, Thetford, UK.

671

672

Robbins, C.S., Bystrak, D. \& Geissler, P.H. 1986. The Breeding Bird Survey: Its first fifteen years, 1965-

673

1979. U.S. Fish. Wildl. Serv., Resour. Publ. 157.

674

675

Sanderlin, J.S., Block, W.M. \& Ganey, J.L. 2014. Optimizing study design for multi-species avian

676

monitoring programmes. J.Appl. Ecol 51:860-870.

677

678

Sauer, J.S., Peterjohn, B.G. \& Link, W.A. 1994. Observer differences in the North American Breeding

Bird Survey. Auk 111:50-62.

680

681

Sim, I.M.W., Campbell, L., Pain, D.J. \& Wilson, J.D. 2000. Correlates of the population increase of

Common Buzzards Buteo buteo in the West Midlands between 1983 and 1996. Bird Study 47:154-

683 164.

684 
buteo density and breeding success in the West Midlands. Bird Study 48:317-329.

687

688

Simpson, V.R. 1993. Causes of mortality and pathological conditions observed in Common Buzzards

689

(Buteo buteo) in Cornwall, England. - In: Dorrestein, G. and van den Bergh (eds), Proc. 1993 Eur.

690

Conf. Avian Med. Surgery. Association of Avian Veterinarians, Utrecht, pp. 423-440.

691

692

Soulé, M. E. (Ed.). 1987. Viable populations for conservation. Cambridge university press.

693

694

Stanbury, A. \& Gregory, R. (2009) Exploring the effects of truncated, pooled and sexed data in

distance sampling estimation of breeding bird abundance. Bird Study 56:298-309

696

697

Stephens, P.A., Pettorelli, N., Barlow, J., Whittingham, M.J, \& Cadotte, M.W. 2015. Management by

proxy? The use of indices in applied ecology. J. Appl. Ecol. 52:1-6

699

700

Thiollay, J.M. 1967. Ecologie d'une population de rapaces diurnes en Lorraine. Terre Vie 114: 116-

701 183.

702

703

Thomas, L., Buckland, S.T., Rexstad, E.A., Laake, J.L., Strindberg, S., Hedley, S.L., Bishop, R.B., Marques, T.A. \& Burnham, K.P. 2010. Distance software: design and analysis of distance sampling surveys for estimating population size. J. Appl. Ecol. 47: 5-14.

706

Thompson, W.L. 2002. Towards reliable bird surveys: Accounting for individuals present but not detected. Auk 119:18-25.

Tubbs, C.R. 1971. The Buzzard. David and Charles. 
712 Walls, S.S. \& Kenward, R.E. 1998. Movements of radio-tagged Buzzards Buteo buteo in early life. Ibis 140:561-568.

714

715

Walls, S.S., Mañosa, S., Fuller, R.M., Hodder, K.H. \& Kenward, R.E. 1999. Is early dispersal enterprise or exile? Evidence from radio tagged buzzards. J. Avian Biol. 30:407-415.

717

718

Wildlife \& Countryside Act 1981, Ch 69, s.1 \& s.16

719

720 Woodward, I.D., Massimino, D., Hammond, M.J., Harris, S.J., Leech, D.I., Noble, D.G., Walker, R.H.,

721 Barimore, C., Dadam, D., Eglington, S.M., Marchant, J.H., Sullivan, M.J.P., Baillie, S.R. \& Robinson,

722 R.A. (2018) BirdTrends 2018: trends in numbers, breeding success and survival for UK breeding birds.

Research Report 708. BTO, Thetford. www.bto.org/birdtrends 


\section{Tables}

725 Table 1. Covariates used in modelling distance sampling estimates of Common Buzzards Buteo buteo

726 in central southern England.

\begin{tabular}{lll}
\hline Covariate & Description & Levels \\
\hline OBS & Fieldworker & Factor - MS or RH \\
LOC & Situation of the bird & Factor - Ground, Perched, Flying \\
STRATA & Section of study area & Factor - East or West \\
TIME & Minutes after sunrise & Continuous \\
WDS & Area $\left(\mathrm{m}^{2}\right)$ of woodland within $250 \mathrm{~m}$ & Continuous \\
& radius of observer location & \\
\hline
\end{tabular}

727

728 

Buteo buteo in central southern England.

\begin{tabular}{ccccccc}
\hline $\begin{array}{c}\text { Transect } \\
\text { Period }\end{array}$ & Season Year & $\begin{array}{c}\text { Number of } \\
\text { transects }\end{array}$ & $\begin{array}{c}\boldsymbol{\Sigma} \text { Transect } \\
\text { lengths } \\
\mathbf{( k m )}\end{array}$ & $\begin{array}{c}\text { Mean } \\
\text { transect } \\
\text { duration } \\
\text { (min) }\end{array}$ & Observations & $\begin{array}{c}\text { Observations } \\
\text { after Truncation } \\
\text { (550m) }\end{array}$ \\
\hline $\mathbf{1}$ & Autumn 2011 & 40 & 594.7 & 320 & 489 & 475 \\
$\mathbf{2}$ & Spring 2012 & 35 & 531.2 & 343 & 611 & 599 \\
$\mathbf{3}$ & Autumn 2012 & 26 & 379.2 & 345 & 359 & 336 \\
$\mathbf{4}$ & Spring 2013 & 25 & 382.2 & 339 & 471 & 445 \\
$\mathbf{5}$ & Autumn 2013 & 39 & 570.3 & 388 & 590 & 565 \\
$\mathbf{6}$ & Spring 2014 & 35 & 523.7 & 404 & 830 & 814 \\
$\mathbf{7}$ & Autumn 2014 & 25 & 373.4 & 363 & 409 & 396 \\
$\mathbf{8}$ & Spring 2015 & 22 & 361.6 & 414 & 437 & 431 \\
$\mathbf{9}$ & Autumn 2015 & 25 & 393.3 & 411 & 469 & 467 \\
$\mathbf{1 0}$ & Spring 2016 & 24 & 379.9 & 384 & 509 & 502 \\
TOTAL & & 299 & 4489.5 & 3711 & 5174 & 5030 \\
\hline
\end{tabular}

731 
Table 3. Details of model selection statistics for distance sampling estimates of the Common Buzzard

Buteo buteo population in central southern England. Preferred models are indicated by bold type.

735 (Period - survey period number, season and year; Engine - analysis engine; Key - key function, U-

737 terms), Cos - Cosine, HP - Hermite polynomial, SP - Simple polynomial; Covariates - included in the

Cramér-von Mises Goodness of fit test value and ( $P$ value))

\begin{tabular}{|c|c|c|c|c|c|c|c|}
\hline Period & Engine & Key & $\begin{array}{l}\text { Adjustment } \\
\text { Term }\end{array}$ & Covariates & Parameters & $\triangle \mathrm{AIC}$ & $\operatorname{CvM}(p)$ \\
\hline \multirow[t]{6}{*}{ (1)AUT 2011} & CDS & $\mathrm{HN}$ & $\operatorname{Cos}(1)$ & - & 2 & 11.52 & - \\
\hline & & $\mathrm{HZ}$ & $\mathrm{HP}(3)$ & - & 5 & 11.72 & - \\
\hline & MCDS & HN & 0 & STRATA TIME WDS & 4 & 0.00 & $0.277(0.1)$ \\
\hline & & $\mathrm{HN}$ & $\mathrm{SP}(1)$ & TIME WDS & 6 & 1.74 & $0.139(0.3)$ \\
\hline & & $\mathrm{HN}$ & $\operatorname{Cos}(1)$ & TIME WDS & 4 & 1.81 & $0.121(0.4)$ \\
\hline & & $\mathrm{HN}$ & $\operatorname{Cos}(1)$ & WDS & 3 & 3.11 & $0.123(0.3)$ \\
\hline \multirow[t]{6}{*}{ (2)SPR2012 } & CDS & $\mathrm{HN}$ & 0 & - & 1 & 1538.46 & $0.011(1.0)$ \\
\hline & & $\mathrm{HZ}$ & $\mathrm{SP}(1)$ & - & 3 & 1541.85 & $0.012(1.0)$ \\
\hline & MCDS & $\mathrm{HN}$ & 0 & STRATA TIME WDS & 4 & 0.00 & $0.038(0.9)$ \\
\hline & & $\mathrm{HN}$ & $\operatorname{Cos}(1)$ & STRATA TIME WDS & 5 & 1.75 & $0.021(1.0)$ \\
\hline & & $\mathrm{HN}$ & 0 & TIME WDS & 3 & 8.99 & $0.036(0.9)$ \\
\hline & & $\mathrm{HN}$ & 0 & TIME & 2 & 26.07 & 0.015 (1.0) \\
\hline \multirow[t]{6}{*}{ (3)AUT2012 } & CDS & $\mathrm{HN}$ & 0 & - & 1 & 13.27 & $0.117(0.4)$ \\
\hline & & $\mathrm{HZ}$ & 0 & - & 2 & 17.45 & $0.124(0.3)$ \\
\hline & MCDS & $\mathrm{HN}$ & 0 & STRATA TIME WDS & 6 & 0.00 & $0.109(0.4)$ \\
\hline & & HN & 0 & WDS & 4 & 0.77 & $0.115(0.4)$ \\
\hline & & $\mathrm{HN}$ & 0 & TIME & 2 & 13.88 & $0.114(0.4)$ \\
\hline & & $\mathrm{HN}$ & 0 & LOC & 3 & 15.95 & $0.114(0.4)$ \\
\hline \multirow[t]{6}{*}{ (4)SPR2013 } & CDS & $\mathrm{HN}$ & $\operatorname{Cos}(1)$ & - & 2 & 18.38 & $0.039(0.9)$ \\
\hline & & $\mathrm{HZ}$ & $\operatorname{Cos}(1)$ & - & 3 & 19.24 & $0.038(0.9)$ \\
\hline & MCDS & HN & $\operatorname{Cos}(1)$ & OBS TIME & 4 & 0.00 & $0.032(0.9)$ \\
\hline & & $\mathrm{HN}$ & $\mathrm{SP}(1)$ & OBS TIME & 4 & 0.11 & $0.070(0.6)$ \\
\hline & & $\mathrm{HN}$ & $\operatorname{Cos}(1)$ & OBS TIME WDS & 5 & 1.82 & $0.031(0.9)$ \\
\hline & & $\mathrm{HN}$ & $\operatorname{Cos}(1)$ & TIME & 3 & 8.10 & $0.030(0.9)$ \\
\hline \multirow[t]{4}{*}{ (5)AUT2013 } & CDS & $\mathrm{HN}$ & 0 & - & 1 & 46.97 & $0.286(0.1)$ \\
\hline & & $U$ & $\mathrm{HP}(1)$ & - & 1 & 49.05 & $0.647(0.01)$ \\
\hline & MCDS & $\mathrm{HN}$ & 0 & $\begin{array}{l}\text { OBS STRATA TIME } \\
\text { WDS }\end{array}$ & 5 & 0.00 & $0.252(0.1)$ \\
\hline & & HN & 0 & OBS TIME WDS & 4 & 0.59 & $0.235(0.15)$ \\
\hline
\end{tabular}




\begin{tabular}{|c|c|c|c|c|c|c|c|}
\hline & & $\mathrm{HN}$ & 0 & TIME WDS & 3 & 1.20 & $0.233(0.15)$ \\
\hline \multirow[t]{6}{*}{ (6)SPR2014 } & CDS & $\mathrm{HN}$ & 0 & - & 1 & 12.45 & $0.106(0.4)$ \\
\hline & & $\mathrm{HZ}$ & $\operatorname{Cos}(1)$ & - & 3 & 14.42 & $0.076(0.6)$ \\
\hline & MCDS & HN & $S P(1)$ & STRATA WDS & 4 & 0.00 & $0.300(0.1)$ \\
\hline & & $\mathrm{HN}$ & $\mathrm{SP}(1)$ & STRATA TIME WDS & 5 & 1.87 & $0.270(0.1)$ \\
\hline & & $\mathrm{HN}$ & $\mathrm{SP}(1)$ & WDS & 3 & 3.42 & $0.191(0.15)$ \\
\hline & & $\mathrm{HN}$ & 0 & WDS & 2 & 3.94 & $0.084(0.5)$ \\
\hline \multirow[t]{5}{*}{ (7)AUT2014 } & CDS & $\mathrm{HN}$ & $\operatorname{Cos}(3)$ & - & 4 & 0.00 & $0.094(0.5)$ \\
\hline & & $\mathbf{U}$ & $\operatorname{Cos}(5)$ & - & 5 & 0.94 & $0.074(0.6)$ \\
\hline & & $\mathrm{HN}$ & $\operatorname{Cos}(2)$ & - & 3 & 11.91 & $0.199(0.15)$ \\
\hline & MCDS & $\mathrm{HN}$ & $\operatorname{Cos}(1)$ & WDS & 3 & 9.02 & $0.34(0.05)$ \\
\hline & & $\mathrm{HN}$ & $\operatorname{Cos}(1)$ & WDD & 5 & 10.99 & $0.314(0.1)$ \\
\hline \multirow[t]{6}{*}{ (8)SPR2015 } & CDS & $\mathrm{HN}$ & $\operatorname{Cos}(2)$ & - & 3 & 110.17 & $0.022(1.0)$ \\
\hline & & $\mathrm{HZ}$ & $\mathrm{SP}(2)$ & - & 4 & 111.16 & $0.020(1.0)$ \\
\hline & MCDS & $\mathrm{HZ}$ & 0 & LOC TIME WDS & 7 & 0.00 & $0.069(0.6)$ \\
\hline & & $\mathrm{HN}$ & $\operatorname{Cos}(2)$ & TIME WDS & 5 & 1.21 & $0.022(1.0)$ \\
\hline & & $\mathrm{HZ}$ & $\mathrm{SP}(1)$ & WDS & 6 & 6.94 & $0.032(0.9)$ \\
\hline & & $\mathrm{HZ}$ & $\mathrm{SP}(1)$ & TIME & 4 & 9.63 & $0.054(0.7)$ \\
\hline \multirow[t]{6}{*}{ (9)AUT2015 } & CDS & $\mathrm{HN}$ & $\mathrm{SP}(1)$ & - & 2 & 10.71 & $0.113(0.4)$ \\
\hline & & $\mathrm{HZ}$ & $\mathrm{HP}(1)$ & - & 3 & 12.92 & $0.101(0.4)$ \\
\hline & MCDS & HN & $S P(1)$ & WDS & 3 & 0.00 & $0.093(0.4)$ \\
\hline & & $\mathrm{HN}$ & $S P(1)$ & STRATA WDS & 4 & 0.82 & $0.091(0.5)$ \\
\hline & & $\mathrm{HN}$ & $\mathrm{SP}(1)$ & TIME WDS & 4 & 1.56 & $0.094(0.5)$ \\
\hline & & $\mathrm{HN}$ & 0 & WDS & 2 & 1.59 & $0.093(0.5)$ \\
\hline \multirow[t]{6}{*}{ (10)SPR2016 } & CDS & $\mathrm{HN}$ & $\mathrm{SP}(1)$ & - & 2 & 5.02 & $0.151(0.3)$ \\
\hline & & $\mathrm{HZ}$ & $\mathrm{SP}(1)$ & - & 3 & 5.26 & $0.063(0.6)$ \\
\hline & MCDS & $\mathrm{HN}$ & 0 & WDS & 4 & 0.00 & $0.087(0.5)$ \\
\hline & & $\mathrm{HN}$ & 0 & TIME WDS & 5 & 1.37 & $0.079(0.5)$ \\
\hline & & $\mathrm{HN}$ & 0 & STRAT WDS & 5 & 1.78 & $0.088(0.5)$ \\
\hline & & $\mathrm{HN}$ & 0 & LOC TIME WDS & 7 & 3.97 & $0.077(0.6)$ \\
\hline
\end{tabular}


743 Table 4. Estimates of density and population size of Common Buzzards Buteo buteo with Lower (LCL)

744 and Upper (UCL) 95\% confidence intervals. \%CV - coefficient of variation, df - degrees of freedom.

745

\begin{tabular}{cccccc}
\hline Year & Period & $\begin{array}{c}\mathrm{LCL}-\text { Density }-\mathrm{UCL} \\
\text { (Individuals km-2) }\end{array}$ & $\mathrm{LCL}-$ No. individuals $-\mathrm{UCL}$ & $\% \mathrm{CV}$ & $\mathrm{df}$ \\
\hline 2011 & Autumn & $0.936-1.111-1.319$ & $2428-2883-3423$ & 8.62 & 65.4 \\
2012 & Spring & $0.836-1.126-1.517$ & $2169-2922-3936$ & 14.81 & 39.2 \\
& Autumn & $0.990-1.274-1.639$ & $2568-3305-4254$ & 12.48 & 35.31 \\
2013 & Spring & $1.327-1.614-1.963$ & $3444-4187-5093$ & 9.66 & 34.58 \\
& Autumn & $1.172-1.393-1.654$ & $3043-3613-4292$ & 8.58 & 50.10 \\
2014 & Spring & $1.458-1.734-2.064$ & $3782-4500-5354$ & 8.66 & 47.94 \\
& Autumn & $1.333-1.695-2.156$ & $3458-4399-5595$ & 11.86 & 32.84 \\
2015 & Spring & $1.176-1.746-2.593$ & $3051-4531-6729$ & 19.70 & 36.58 \\
& Autumn & $1.342-1.705-2.164$ & $3483-4423-5616$ & 11.77 & 32.45 \\
& Spring & $1.445-1.728-2.068$ & $3749-4485-5365$ & 8.82 & 32.15 \\
\hline
\end{tabular}

746

747 


\section{Legends to Figures}

749

750 Figure 1. Study area in central southern England showing randomised locations of the Idealised

751 Transect Routes (ITRs) for the first survey of Common Buzzards Buteo buteo in autumn 2011.

752 Shading represents urban areas.

753

754

755 Figure 2. Estimates of Common Buzzard Buteo buteo population size within the study area in central

756 south England for each survey period between autumn 2011 and spring 2016 ( \pm 95\% confidence

757 intervals).

758

759

760

761 


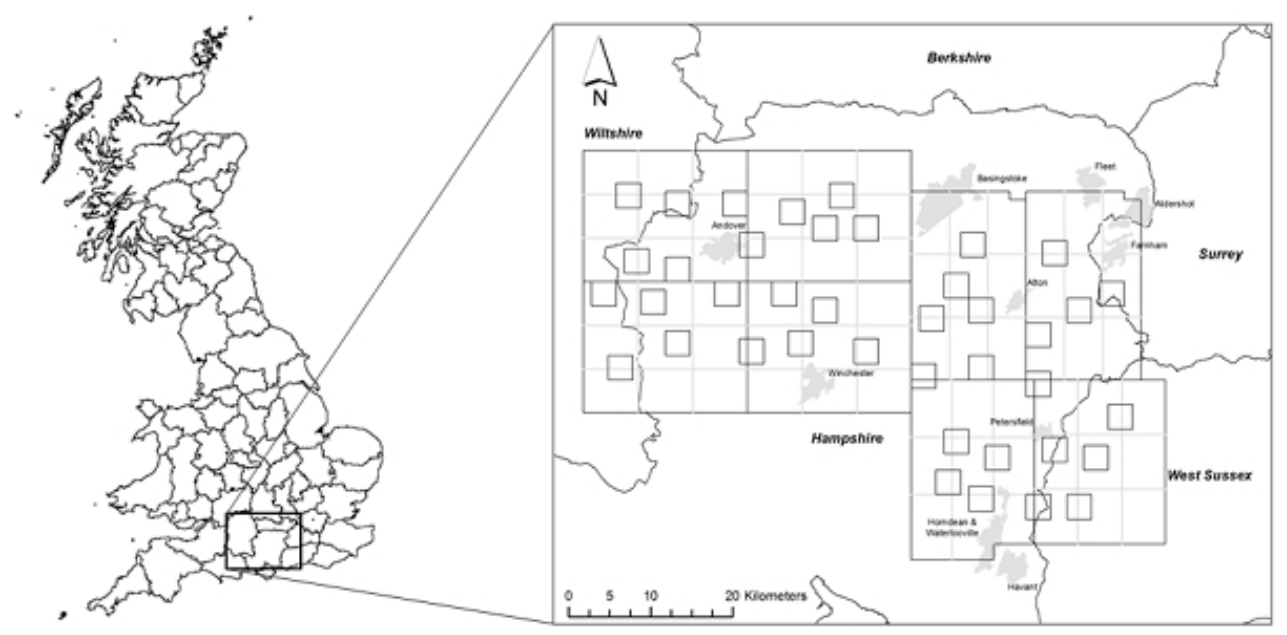

Figure 1. Study area in central southern England showing randomised locations of the Idealised Transect Routes (ITRs) for the first survey of Common Buzzards Buteo buteo in autumn 2011. Shading represents urban areas.

$164 \times 83 \mathrm{~mm}(96 \times 96 \mathrm{DPI})$ 


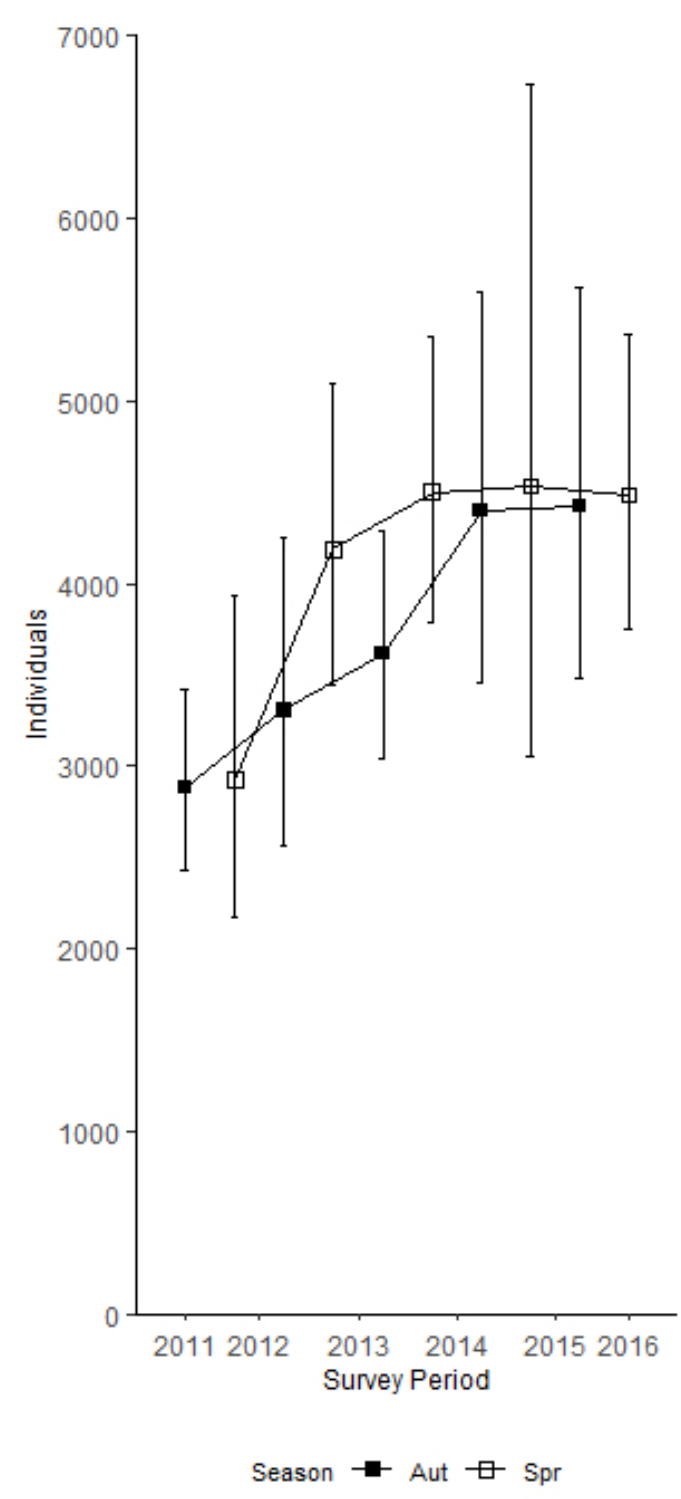

Figure 2. Estimates of Common Buzzard Buteo buteo population size within the study area in central south England for each survey period between autumn 2011 and spring 2016 ( $\pm 95 \%$ confidence intervals).

$81 \times 185 \mathrm{~mm}(96 \times 96 \mathrm{DPI})$ 